\title{
PLATELET COUNT TO SPLEEN DIAMETER RATIO AND TO SPLEEN AREA RATIO AS PREDICTORS FOR ESOPHA-GEAL VARICES IN CHRONIC HEPATITIS C PATIENTS WITH LIVER CIRRHOSIS
}

\section{By}

ASHRAF M ALBREEDY

Department of Tropical Medicine, Faculty of Medicine, Ain Shams University, Cairo 11566, Egypt (drashrafbreedy@yahoo.com, mobile: 0020100-3210054)

\begin{abstract}
Endoscopic detection of esophageal varices (EV) especially the high risk esophageal varices (HREV) is recommended in cirrhotic patients. There are several studies about non-invasive markers to predict the presence of EV. The aim of this study was to evaluate platelet count to spleen diameter $(\mathrm{P} / \mathrm{D})$ ratio and platelet count to spleen area $(\mathrm{P} / \mathrm{A})$ ratio as predictors for EV and HREV in patients with liver cirrhosis. This prospective study included 100 cirrhotic patients without previous variceal hemorrhage or endoscopic intervesion. Biochemical, imaging and endoscopic findings were collected in all patients. Several parameters including $\mathrm{P} / \mathrm{D}$ and $\mathrm{P} / \mathrm{A}$ ratio were measured and their association with the presence of EV and HREV was tested.

The results showed that only $\mathrm{P} / \mathrm{D}$ and $\mathrm{P} / \mathrm{A}$ ratios were found to be independent predictors for the presence of EV and HREV in multivariant analysis. For prediction of the $\mathrm{EV}$ formation in cirrhotic patients, $\mathrm{P} / \mathrm{D}$ ratio at value $\leq 979.9$ and $\mathrm{P} / \mathrm{A}$ ratio of $\leq 20.6 \mathrm{had}$ area under the curve (AUC) 0.922 and 0.975 respectively with sensitivity $100 \%$, specificity $30 \%$ for $\mathrm{P} / \mathrm{D}$ ratio and sensitivity $100 \%$, specificity $75 \%$ for $\mathrm{P} / \mathrm{A}$ ratio. For prediction of the HREV formation, $\mathrm{P} / \mathrm{D}$ ratio at value $\leq \leq 587.9$ and $\mathrm{P} / \mathrm{A}$ ratio of $\leq 13.7 \mathrm{had}$ AUC 0.867 and 0.991 respectively with sensitivity $100 \%$, specificity $50 \%$ for $\mathrm{P} / \mathrm{D}$ ratio and sensitivity $100 \%$, specificity $88 \%$ for $\mathrm{P} / \mathrm{A}$ ratio.

Key words: liver cirrhosis, esophageal varices, platelet count/spleen area ratio, platelet count/spleen diameter ratio
\end{abstract}

\section{Introduction}

Portal hypertension commonly accompanies the presence of liver cirrhosis, and the development of esophageal varices $(\mathrm{EV})$ is one of its major complications. Variceal haemorrhage occurs in 25 to $40 \%$ of patients with cirrhosis and varices (Grace, 1992), the frequency of bleeding from large varices is 30\%-53\% compared with 5\%-18\% for small varices (De Franchis, 2003). The mortality from each episode of variceal bleeding is estimated to be $17-57 \%$ (Jensen, 2002). This makes the prevention of esophageal variceal bleeding the is cornerstone of long-term management of patients with liver cirrhosis (Garcia-Tsao et al, 2007)

All guidelines recommended that cirrhotic patients should be screened by esophago-gastro-doudenoscopy (EGD) for the EV when liver cirrhosis is diagnosed (Garcia-Tsao et al, 2007; De Franchis, 2010). These recommendations imply a considerable burden on endoscopies and related costs as they require that patients repeatedly undergo an unpleasant invasive procedure, even by the majority of subjects undergoing screening EGD either do not have varices or have varices that do not require prophylactic therapy (D'amico G and Morabito, 2004). Therefore, considerable interest in developing models to predict the presence of esophageal varices especially high risk varices by non-endoscopic methods.

This study evaluated of the utility of the platelet count/spleen diameter $(\mathrm{P} / \mathrm{D})$ ratio and platelet count/spleen area $(\mathrm{P} / \mathrm{A})$ ratio as non-invasive predictors for the $\mathrm{EV}$ in cirrhotic patients and in detecting patients with high risk esophageal varices.

\section{Patients, Materials and Methods}

This prospective cross sectional study was performed at Ain shams university hospitals. One hundred patients were selected and enrolled in this study from 
Tropical Medicine department, Tropical outpatient clinic at Ain Shams University hospitals, Cairo, Egypt during the interval between October 2013 and October 2014. Diagnosis of liver cirrhosis was based on clinical, biochemical, imaging and/or histopathological back-ground. All patients gave their informed consent to participate. The study was conducted in accordance with the ethical guidelines of Declaration of Helsinki and the International Conference on Harmonization Guidelines for Good Clinical Practice. The study was accepted by ethical research committee in Ain Shams University Medical Faculty.

Patients with unstable active or previous gastrointestinal bleeding from esophagral varices, previous band ligation, variceal scleratherapy, transjugular intrahepatic portosystemic stent shunt, pharmacological treatment (beta blockers) or surgery for portal hypertension were excluded from the study. Patients with portal vein thrombosis, hepatocellular carcinoma or advanced other organ malignancy, other with severe medical condition or with other causes of splenomegaly or thrombocytopenia were also excluded.

All patients were subjected to full history taking, complete clinical and biochemical examinations: $\mathrm{CBC}$, Liver profile tests (ALT, AST, Albumin, PT, alkaline phosphatase, total bilirubin, INR). Abdomen ultrasonography by single expert operator using real time scanner (SSA 270A; Toshiba ${ }^{\circledR}$, Japan) equipped with a Toshiba PLB-308M 4MHz probe. All were fasting for at least 6 hours before examination to evaluate the ascites, focal lesions, bipolar splenic diameter in millimetres and spleen width in millimetres.

The definition of spleen diameter is the maximum transverse distance between two poles in millimeters; spleen width is the maximum vertical distance across the splenic hilum at the level of spleen diameter in millimetres. Spleen area was calculated from spleen diameter multiplied by spleen width, platelet count/spleen diameter ratio was calculated by platelet count $(/ \mathrm{mcl})$ divided by spleen diameter (mm) and platelet count/spleen area ratio was calculated by platelet count $(/ \mathrm{mcl})$ divided by spleen area (mm2).

Upper gastrointestinal endoscopy, using Pentax ${ }^{\circledR}$ EPK-i5000 video endoscope was performed at Ain Shams endoscopy unit by an endoscopist, who was blinded to the patient's data. Examinations of oesophageal varices were performed. All patients were fasting at least 8 hours before endoscopic examination to evaluate the presence or absence of EV. EV was classified according to AASLD practice guidelines; no varices, small and large varices (Garcia-Tsao et al, 2007). The EV were classified into high risk (HREV) and no HREV; HREV included large EV with or without red color signs or small varices with red color signs; red wale or cherry red spots (Sarin et al, 1989)

The duration of initial clinical assessment, biochemical study, endoscopic evaluation and spleen measurement was performed within 2 weeks for each patient.

Statistical methods: Statistics were performed on IBM-compatible computer using SPSS 16.5 software package. Continuous data were presented in the form of mean \pm SD or median; range. Categorical data were presented in the form of number and percentage. Comparisons between groups of continuous data parameters were done using Student t-test ( $\mathrm{t}$ value) for normally distributed parameters and Mann Whitney $U$ test for nonparametric data distribution ( $\mathrm{z}$ value). Comparisons between groups and associations of categorical data parameters were performed by using chi square test or Fisher exact test ( $\mathrm{x}^{2}$ value). Receiver operating characteristic curves (ROC curves) was applied to find the best sensitivity and specificity cut off values. Model validity was measured by the area under the curve (AUC). The probability of error $<0.05$ was considered significant. Predictive factors that were determined to be significant by univariate analysis were 
then subjected to multivariate analyses using logistic regression analyses

\section{Results}

A total 100 cirrhotic patients were selected in this study. They were 58 males and 42 females with mean age $44.24 \pm 7.05$ years old. According to the endoscopic findings our patients were initially divided into two groups according to the presence of EV: patients with positive EV included $66(66 \%)$ patients and patients with negative EV included 34 (34\%) patients. Subanalysis of patients with EV was divided into 2 groups: patients with high risk esophageal varices (HREV) included $47(47 \%)$ patients and patients with non-high risk esophageal varices included 19 (19\%) patients. Patients with positive EV had significant higher ultrasound spleen diameter (159.8 vs. 135.5 $\mathrm{mm})$, width (61.5 vs. $39.2 \mathrm{~mm})$, area $\left(9876.92\right.$ vs. $\left.5363.22 \mathrm{~mm}^{2}\right)$ and APRI (2.57 vs. 2.003) when compared to those without EV $(\mathrm{P}<0.05)$. Patients with positive $\mathrm{EV}$ had lower mean platelet count (107.894 vs. 178.118 thousand $\left./ \mathrm{mm}^{3}\right)$, $\mathrm{P} / \mathrm{D}$ ratio (686.29 vs. 2003.65) and $\mathrm{P} / \mathrm{A}$ ratio (11.316 vs. 36.359) as compared to those without EV $(\mathrm{P}<0.05)$. Also, patients with esophageal varices had more significant advanced liver disease according to Child class when compared to those without, where 29 patients (85.29\%) without esophageal varices were Child

Table 1: comparison between patients with and without esophageal varices (EV):

\begin{tabular}{|l|l|l|l|}
\hline & Negative EV (34) & Positive EV $(66)$ & p-value \\
\hline Age $(\mathrm{y})$ & $43.059 \pm 4.748$ & $44.509 \pm 4.563$ & 0.061 \\
\hline HB $(\mathrm{g} / \mathrm{dl})$ & $11.718 \pm 1.661$ & $11.011 \pm 1.966$ & 0.076 \\
\hline WBCs $(/ \mathrm{mcl})$ & $6.229 \pm 2.083$ & $6.259 \pm 2.521$ & 0.953 \\
\hline Platelet count $/ \mathrm{mcl})$ & $178.118 \pm 33.877$ & $107.894 \pm 26.715$ & $<0.001$ \\
\hline ALT $(\mathrm{U} / \mathrm{L})$ & $94.794 \pm 54.003$ & $74.894 \pm 36.693$ & 0.132 \\
\hline AST $($ U/L) & $105.382 \pm 51.603$ & $84.818 \pm 41.789$ & 0.134 \\
\hline S. Creatinine & $0.912 \pm 0.198$ & $0.964 \pm 0.198$ & 0.218 \\
\hline Spleen diameter $(\mathrm{mm})$ & $135.529 \pm 12.885$ & $159.848 \pm 13.650$ & $<0.001$ \\
\hline Spleen width $(\mathrm{mm})$ & $39.221 \pm 6.848$ & $61.574 \pm 9.851$ & $<0.001$ \\
\hline Spleen area $(\mathrm{mm})$ & $5363.22 \pm 1145.68$ & $9876.92 \pm 2030.37$ & $<0.001$ \\
\hline P/D ratio & $2003.65 \pm 4108.49$ & $686.29 \pm 197.13$ & $<0.001$ \\
\hline P/A ratio & $36.359 \pm 15.809$ & $11.316 \pm 3.448$ & $<0.001$ \\
\hline APRI & $2.003 \pm 0.917$ & $2.574 \pm 1.484$ & 0.043 \\
\hline male/female & $15 / 19$ & $36 / 30$ & 0.323 \\
\hline Child class A/B/C & $29 / 5 / 0$ & $12 / 28 / 26$ & $<0.001$ \\
\hline
\end{tabular}

class A while only 12 patients $(18.18 \%)$ with esophageal varices were Child A at presentation $(\mathrm{P}<0.05)$.

The multivariate analysis showed that only $\mathrm{P} / \mathrm{D}$ ratio and $\mathrm{P} / \mathrm{A}$ ratio were independent predictors for the EV presence. The $\mathrm{P} / \mathrm{D}$ ratio of $\leq 979.9$ was the best cutoff value to predict the presence of $\mathrm{EV}$ in cirrhotic patients and the area under the curve (AUC) was 0.922 with sensitivity $100 \%$, specificity $30 \%$, the negative predictive value (NPV) 100\%, the positive predictive value (PPV) $95.5 \%$ and accuracy $92.2 \%$. The $\mathrm{P} / \mathrm{A}$ ratio of $\leq 20.6$ was the best cut off value for prediction of the $\mathrm{EV}$ formation in cirrhotic patients and AUC was 0.975 with sensitivity $100 \%$, specificity $75 \%$, NPV 100\%, PPV 97.1\% and the accuracy of test was $97.5 \%$.

Patients with evidence of HREV had significant higher ultrasound spleen diameter $(162.38$ vs. $153.57 \mathrm{~mm})$, width (62.74 vs. $58.68 \mathrm{~mm})$ and area (10223.29 vs. 9020.11) when compared to patients with no HREV $(<0.05)$. Patients with positive HREV had lower mean platelet count (101.15 vs. $124.58 / \mathrm{mcl}), \mathrm{P} / \mathrm{D}$ ratio (629.27 vs. 827.32) and $\mathrm{P} / \mathrm{A}$ ratio (10.25 vs. 13.95) when compared to those without and the difference was statistically significant (0.05). Also, patients with HERV had more significant advanced liver disease according to Child class when compared to those without. 
ALT: Alanine Transaminase. 11111AST: Aspartate Transaminase. ALP: Alkaline phosphatase. PVD: Portal vein diameter. SD: spleen diameter. P/D ratio: Platelet count/spleen Diameter ratio. P/A ratio: Platelet count/spleen Area ratio. APRI: Aspartate transaminase-to-Platelet Ratio Index.

Table 2: multivariate analysis of variables associated with presence of EV.

\begin{tabular}{|c|c|c|c|c|}
\hline \multirow{2}{*}{} & \multirow{2}{*}{ P-value } & \multirow{2}{*}{ Odd } & \multicolumn{2}{|c|}{$95 \%$ CI for odd } \\
\cline { 3 - 5 } & & & Lower & Upper \\
\hline P/D ratio & 0.014 & 1.512 & 1.000 & 1.955 \\
\hline P/A ratio & 0.005 & 0.711 & 0.539 & 0.945 \\
\hline
\end{tabular}

Multivariate analysis included variables: Child-Pugh class, platelet count, spleen diameter, spleen width, platelet count/ spleen diameter, platelet count/spleen area and APRI.

Table 3: Diagnostic performance of the best cutoff values of platelet count/ spleen diameter ratio, platelet count/ spleen area ratio and APRI in the diagnosis of esophageal varices.

\begin{tabular}{|c|c|c|c|c|c|c|}
\hline Variable & Cutoff & Sensitivity & Specificity & PPV & NPV & Accuracy \\
\hline P/D ratio & $\leq 979.9$ & 100 & 30 & 95.5 & 100 & 92.2 \\
\hline P/A ratio & $\leq 20.6$ & 100 & 75 & 97.1 & 100 & 97.5 \\
\hline
\end{tabular}

NPV: negative predictive value, PPV: positive predictive value

Table 4: comparison between patients with and without HREV

\begin{tabular}{|l|c|c|c|}
\hline \multirow{2}{*}{ Age $(\mathrm{y})$} & \multicolumn{2}{|c|}{ HREV } & p-value \\
\cline { 2 - 3 } & $44.895 \pm 5.896$ & $45.532 \pm 6.157$ & 0.07 \\
\hline WB $(\mathrm{g} / \mathrm{dl})$ & $12.053 \pm 1.395$ & $10.589 \pm 2.018$ & 0.115 \\
\hline Platelet count//mcl) & $6.868 \pm 2.174$ & $6.013 \pm 2.629$ & 0.214 \\
\hline ALT $(\mathrm{U} / \mathrm{L})$ & $124.579 \pm 23.092$ & $101.149 \pm 25.265$ & 0.001 \\
\hline AST $(\mathrm{U} / \mathrm{L})$ & $76.474 \pm 40.952$ & $74.255 \pm 35.281$ & 0.826 \\
\hline S. Creatinine & $84.579 \pm 46.932$ & $84.915 \pm 40.072$ & 0.977 \\
\hline Spleen diameter $(\mathrm{mm})$ & $0.889 \pm 0.213$ & $0.994 \pm 0.186$ & 0.052 \\
\hline Spleen width $(\mathrm{mm})$ & $153.579 \pm 8.578$ & $162.383 \pm 14.549$ & 0.016 \\
\hline Spleen area $(\mathrm{mm} 2)$ & $58.684 \pm 5.733$ & $62.743 \pm 10.928$ & 0.013 \\
\hline P/D ratio & $9020.11 \pm 1050.63$ & $10223.29 \pm 2228.79$ & 0.028 \\
\hline P/A ratio & $827.321 \pm 196.145$ & $629.272 \pm 168.285$ & $<0.001$ \\
\hline APRl & $13.953 \pm 2.733$ & $10.250 \pm 3.137$ & $<0.001$ \\
\hline male/female & $2.189 \pm 1.425$ & $2.730 \pm 1.494$ & 0.183 \\
\hline Child class $A / B / C$ & $10 / 9$ & $33 / 14$ & 0.175 \\
\hline
\end{tabular}

HREV: High Risk Esophageal Varices. HB: Hemoglobin. WBCs: White Blood Cells. P/D ratio: Platelet count/spleen Diameter ratio. P/A ratio: Platelet count/spleen Area ratio. APRI: Aspartate transaminase-toPlatelet Ratio Index.

Table 5: multivariate analysis of variables associated with presence of HREV.

\begin{tabular}{|c|c|c|c|c|}
\hline \multirow{2}{*}{} & \multirow{2}{*}{ P-value } & \multirow{2}{*}{ Odd } & \multicolumn{2}{|c|}{$95.0 \%$ C. I. for odd } \\
\cline { 4 - 5 } & & & Lower & Upper \\
\hline P/D ratio & 0.032 & 1.00 & 1.00 & 1.01 \\
\hline P/A ratio & 0.004 & 0.41 & 0.25 & 0.75 \\
\hline
\end{tabular}

Multivariate analysis included following variables: Child-Pugh class, diameter, platelet count, spleen diameter, spleen width, platelet count/ spleen diameter, platelet count/spleen area and APRI.

Table 6: Diagnostic performance of best cut off values of platelet count/ spleen diameter ratio, platelet count/ spleen area ratio and APRI in the diagnosis of HREV

\begin{tabular}{|l|l|l|l|l|l|l|}
\hline & Cut-off & Sensitivity & Specificity & PPV & NPV & Accuracy \\
\hline P/D ratio & $\leq 587.9$ & 100 & 50 & 42.2 & 100 & 86.7 \\
\hline P/A ratio & $\leq 13.7$ & 100 & 88 & 83.3 & 100 & 99.1 \\
\hline
\end{tabular}

By multivariate analysis, only $\mathrm{P} / \mathrm{D}$ ratio and $\mathrm{P} / \mathrm{A}$ ratio were independent risk factors for development of HREV. ROC curves were constructed in order to find the best cut off value for the variables independently associated with the presence of EV in multivariate analysis. P/D ratio of $\leq 587.9$ was the best cut-off value 
to predict HREV and AUC was 0.867 with sensitivity $100 \%$, specificity $50 \%$, NPV $100 \%$, PPV $42.2 \%$ and accuracy $86.7 \%$. Platelet count/ spleen area ratio of $\leq 13.7$ was the best cut off for HREV prediction and AUC was 0.991with sensitivity $100 \%$, specificity $88 \%$, NPV $100 \%$, PPV $83.3 \%$ and accuracy was $99.1 \%$.

\section{Discussion}

Liver cirrhosis is a major health problem in Egypt, especially complicating viral hepatitis. Chronic HCV is one of the main causes of liver cirrhosis and liver cancer in Egypt, where it represents the highest prevalence of hepatitis $\mathrm{C}$ in the world; (14.7\%) (Cuadros et al, 2014). Bleeding from esophago-gastric varices is the most important complication of cirrhosis (D'Amico et al, 2006). The first crucial step in prevention is to identify the patients at risk for bleeding by endoscopic screening, in order to select them for prophylactic treatment (Garcia-Tsao et al, 2007). It was estimated that 100 screening endoscopy need to be performed to prevent 1-2 cases of variceal bleeding (Boyer, 1997). Therefore, identification of non-invasive parameters that can accurately predict EV and help identifying patients at greatest risk is important as this might help relieve medical, social, and economic costs especially in developing countries like Egypt. In our study, $66(66 \%)$ of patients had EV and 47 of them $(71.2 \%)$ had HREV. This result is similar to the range of $24 \%$ to $80 \%$ showed in literature (de Franchis and Dell'Era, 2007) and showed that a significant part of cirrhotic patients were unnecessary.

In this study, patients with EV and HREV had significantly more advanced liver disease (Child class B and C) than those without. These results indicate that the patients with Child B and C cirrhosis are at a higher risk of development of varices and higher risk of bleeding, and coincide with Zaman et al. (2001) who found the percentage of HREV in Child $\mathrm{C}$ patients higher than in Child $\mathrm{B}$ pa- tients. Also, Barrera et al. (2009) reported significant higher child score in patients with HREV than those without.

The mean platelet count was significantly lower in the patients with varices in the present study than those without $(p<0.001)$ and agreed with many studies (Schepis et al, 2001; Giannini et al, 2006; Abu El Makarem et al, 2011; González-Ojeda et al, 2014). Also, Platelet count was significantly lower among patients with HREV than those without HREV (101.15 $\pm 25.27 \mathrm{v} / \mathrm{s} 124.58 \pm 23.09$; $\mathrm{p}=0.001)$ and this was statistically significant. This finding agreed with Barrera et al.(2009) who studied a total of 67 patients for prediction of HREV and reported that platelet count was significantly lower among patients with HREV ( $96.3 \pm 46.4$ vs. $164 \pm 80.9 ; p=0.0006$ ).

The present study revealed that patients with EV had significantly larger spleen diameter $(\mathrm{P}<0.001)$ when compared to patients without EV. This result agreed with many studies (Thomopoulos et al, 2003; Giannini et al, 2006; Plianklin et al, 2006; Abu El Makarem et al, 2011; González-Ojeda et al, 2014), while disagreed with others (Zaman et al, 1999; Pilette et al, 1999; Schepis et al, 2001). These discrepancies may be due to difference in the aetiology and the stage of liver cirrhosis of the studied population. Larger spleen diameter was also observed in this study in HREV patients compared without HREV patients (162.38 \pm 14.55 $\mathrm{v} / \mathrm{s} 153.58 \pm 8.58 ; \mathrm{p}=0.016)$ and this was statistically significant. This result agreed with Barrera et al. (2009) who reported that spleen diameter was significantly larger among patients with HREV.

As regards APRI, patients with EV and HREV had significant higher values than those without. In contrast, no association was found between APRI and the presence of EV or HREV on multi-variant analysis. This result was close to Sebastiani et al (2010), who reported a poor performance of APRI for prediction of 
EV and a weak correlation between APRI and the presence of large varices.

In the present study, there was significant decrease in $\mathrm{P} / \mathrm{D}$ ratio in patients with EV over those without EV $(p<0.001)$. The sensitivity of $\mathrm{P} / \mathrm{D}$ ratio for prediction of EV was $100 \%$, specificity was $30 \%$ and the accuracy of the test was $92.2 \%$ under the receiver operating characteristic curve (area under the curve (AUC) = 0.922 ) with the best cut off point value at 979.9. Those results more or less agreed with many studies (Giannini et al, 2006; Plianklin et al, 2006; Agha et al, 2009; Abu El Makarem et al, 2011; GonzálezOjeda et al, 2014). These differences might arise from different racial characteristics, underlying aetiology and extent of the liver disease of the studied population. A meta-analysis which studied the performance of $\mathrm{P} / \mathrm{D}$ ratio for diagnosis of EV in cirrhosis (Chawla et al, 2012) included 1275 patients, reported a sensitivity of $89 \%(95 \%$ CI: $87-92)$ and specificity of $74 \%$ (95\%CI: $70-78)$. Others, which included 20 studies (3,063 patients), found that the hierarchical summary receiver operating characteristic of the P/D for EV was 0.95 at various thresholds and $\mathrm{P} / \mathrm{D}$ ratio can identify $\mathrm{EV}$ in cirrhosis with a high accuracy and emphasized that application of this index, may decrease the need for endoscopy among cirrhotic patients (Ying et al, 2012).

Furthermore in the present study, the P/D ratio of $\leq 587.9$ was the best cut-off value to predict the presence of HREV and the AUC was 0.867 with sensitivity $100 \%$, specificity 50\%, NPV 100\%, PPV $42.2 \%$ and the accuracy $86.7 \%$. This is close to Barrera et al. (2009) who found that at $\mathrm{P} / \mathrm{D}$ ratio of $\leq 830.8$, the NPV of $\mathrm{P} / \mathrm{D}$ ratio for presence of HREV was $77.8 \%$, PPV was 71.4 , sensitivity was $76.9 \%$, specificity was $74.2 \%$ with $\mathrm{c}$ index of $0.78 \%$. The only discrepancy between the present data and their data was that the later found that age was independently associated with presence of HREV beside P/D ratio, while in the present study higher age was associated with presence of HREV in univariant analysis and only $\mathrm{P} / \mathrm{D}$ and $\mathrm{P} / \mathrm{A}$ ratios were the only significant independent predictors of HREV. On the other hand, Schwarzenberger et al. (2010) reported that using P/D ratio with a cut-off value of 909, yielded low PPV and NPV. Other study revealed that the sensitivity of $\mathrm{P} / \mathrm{D}$ ratio to predict $\mathrm{EV}$ was $77.5 \%$, specificity was $45.5 \%$, PPV was $79.5 \%$, the NPV was $42.6 \%$ and the accuracy was $68.9 \%$. Besides this, in their multivariate analysis, P/D ratio did not even correlate with the existence of $\mathrm{EV}$ (Mattos et al, 2010).

In the present study, P/A ratio was significantly lower in those patients with EV and HREV when compared to those without $(11.32 \pm 3.45$ vs. $36.36 \pm 15.81$ and $10.25 \pm 3.14$ vs. $13.95 \pm 2.73, \mathrm{P}<0.001)$ respectively. At a cut off value of 20.6, the AUC of $\mathrm{P} / \mathrm{A}$ ratio for predicting $\mathrm{EV}$ in cirrhotic patients was 0.975 with sensitivity $100 \%$, specificity $75 \%$, NPV $100 \%$, PPV $97.1 \%$ and the accuracy of test was 97.5\%. This finding agreed Plianklin et al. (2006), who found that the NPV of $\mathrm{P} / \mathrm{A}$ ratio for presence of $\mathrm{EV}$ was $100 \%$, PPV was $75 \%$, sensitivity was $100 \%$, specificity was $68 \%$ and the accuracy of the test was $84 \%$ at a cut off value of 21.5. Concerning detection of HREV, $\mathrm{P} / \mathrm{A}$ ratio of $\leq 13.7$ was the best cut off value for prediction of the HREV and AUC was 0.991 with sensitivity $100 \%$, specificity $88 \%$, NPV $100 \%$, PPV $83.3 \%$ and the accuracy of test was $99.1 \%$.

\section{Conclusion}

This study detected the most risky patients with liver cirrhosis were those whom upper endoscopy should be done, i.e.: patients with HREV, using noninvasive parameters. Thus, the sensitivity of both $\mathrm{P} / \mathrm{D}$ and $\mathrm{P} / \mathrm{A}$ were excellent $(100 \%)$ for detection of EV and HREV in cirrhotic patients. However, the $\mathrm{P} / \mathrm{D}$ ratio has a lower specificity than that of $\mathrm{P} / \mathrm{A}$ ratio $(30 \%$ vs. $75 \%)$ respectively for detection of EV and (50\% vs. $88 \%$ ) respectively for detection of HREV. The differ- 
ence in shape of spleen in difference cirin $\mathrm{P} / \mathrm{D}$ ratio. Also, when splenomegaly occurred, it could be enlarged in all directions Both $\mathrm{P} / \mathrm{D}$ and $\mathrm{P} / \mathrm{A}$ ratios were good predictors for presence of EV and HREV. Moreover, P/A ratio had higher specificity than $\mathrm{P} / \mathrm{D}$ ratio.

The author declares no conflict of interest.

\section{References}

Abu El Makarem, MA, Shatat, ME, Shaker, Y, Abdel Aleem, AA, El Sherif, AM, et al, 2011: Platelet count/bipolar spleen diameter ratio for the prediction of esophageal varices: The special Egyptian situation: Noninvasive prediction of esophageal varices. Hepat. Mon. 11, 4:278-84.

Agha, A, Anwar, E, Bashir, K, Savarino, V, Giannini, EG, 2009: External validation of the platelet count/ spleen diameter ratio for the diagnosis of esophageal varices in hepatitis $\mathrm{C}$ virus-related cirrhosis. Dig. Dis. Sci. 54: 654-60.

Barrera, F, Riquelme, A, Soza, A, Contreras, A, Barrios, G, et al, 2009: Platelet count/ spleen diameter ratio for non-invasive prediction of high risk esophageal varices in cirrhotic patients. Ann. Hepatol. 8:325-30.

Boyer, TD, 1997: Natural history of portal hypertension. Clin. Liver Dis. 1, 1:31-44.

Chawla, S, Katz, A, Attar, BM, Gupta, A, Sandhu, DS, et al, 2012: Platelet count/ spleen diameter ratio to predict the presence of esophageal varices in patients with cirrhosis: A systematic review. Eur. J. Gastroenterol. Hepatol. 24:431-6

Cuadros, DF, Branscum, AJ, Miller, FD, Abu-Raddad, LJ, 2014: Spatial epidemiology of hepatitis C virus infection in Egypt: Analyses and Implications. Hepatol. 60: 1150-9.

D'amico, G, Morabito, A, 2004: Non-invasive markers of esophageal varices: Another round, not the last. Hepatol. 39:30-4

D'Amico, G, Garcia-Pagan, JC, Luca, A, Bosch, J, 2006: Hepatic vein pressure gradient reduction and prevention of variceal bleeding in cirrhosis: a systematic review. Gastroentero-logy 131, 5:1611-24.

De Franchis, R, 2003: Evaluation and follow-up of patients with cirrhosis and oesophageal varices. J. Hepatol. 38: 361-3. rhotic patients might affect the specificity De Franchis, R, 2010: Revising consensus in portal hypertension: report of the Baveno $\mathrm{V}$ consensus workshop on methodology of diagnosis and therapy in portal hypertension. J. Hepatol. 53:762

de Franchis, R, Dell'Era, A, 2007: Diagnosis and therapy of esophageal vascular disorders. Curr. Opin. Gastroenterol. 23:422-7.

Garcia-Tsao, G, Sanyal, AJ, Grace, ND, Cary, W, 2007: Practice Guidelines Committee of the American Association for the Study of Liver Diseases; Practice Parameters Committee of the American College of Gastroenterology: Prevention and management of gastroesophageal varices and variceal hemorrhage in cirrhosis. Hepatol. 46:922-38

Giannini, E, Zaman, A, Kreil, A, Floreani, A, Dulbecco, P, et al, 2006: Platelet count /spleen diameter ratio for the noninvasive diagnosis of esophageal varices: Results of a multicenter, prospective, validation study. Am. J. Gastroenterol. 101, 11:2511-19.

González-Ojeda, A, Cervantes-Guevara, G, Chávez-Sánchez, M, Dávalos-Cobián, C, Ornelas, S, et al, 2014: Platelet count/ spleen diameter ratio to predict esophageal varices in Mexican patients with hepatic cirrhosis. Wld. Gastroenterol. 28, 8:2079-84.

Grace, ND, 1992: Prevention of initial variceal haemorrhage. Gastroenterol. Clin. North Am. 21:149

Jensen, DM, 2002: Endoscopic screening for varices in cirrhosis: findings, implications, and outcomes. Gastroenterology 122, 6:162030.

Mattos, AZ, Mattos, AA, Vianna, FF, Musskopf, MI, Pereira-Lima, JC, et al, 2010: Platelet count/spleen diameter ratio: Analysis of its capacity as a predictor of the existence of esophageal varices. Arq. Gastroenterol. 47:275-8.

Pilette, C, Oberti, F, Aube, C. 1999: Noninvasive diagnosis of esophageal varices in chronic liver disease. J. Hepatol. 31:867-73.

Plianklin, S, Leethochawalit, M, Sethasine, $\mathrm{S}$, Wangwinyuvirat, $\mathrm{M}$, Boonsirichan, $\mathrm{R}$. 2006: Utility of platelet count/spleen area ratio to predict the presence of esophageal varices. Thai. J. Gastroenterol. 7:93-9.

Sarin, SK, Sundaram, KR, Ahuja, RK, 1989: Predictors of variceal bleeding: an analysis of clinical, endoscopic, and haemodynamic variables, with special reference to intravariceal pressure. Gut 30, 12:1757-64. 
Schepis, F, Cammà, C, Niceforo, D, Magnano, A, Pallio, S, et al, 2001: Which patients with cirrhosis should undergo endoscopic screening for esophageal varices detection? Hepatology $33,2: 333-8$.

Schwarzenberger, E, Meyer, T, Golla, V, Sahdala, NP, Min, AD, 2010: Utilization of platelet count spleen diameter ratio in predicting the presence of esophageal varices in patients with cirrhosis. J. Clin. Gastroenterol. 44, 2:146-50.

Sebastiani, G, Tempesta, D, Fattovich, G, Castera, L, Halfon, P, et al, 2010: Prediction of esophageal varices in hepatic cirrhosis by simple serum non-invasive markers: Results of a multi-center, large-scale study. J. Hepatol. 53, 4:630-8.
Thomopoulos, K, Labropoulou-Karatza, C, Mimidis, K, Katsakoulis, EC, Iconomou, G, et al, 2003: Non-invasive predictions of the presence of large esophageal varices in patients with cirrhosis. Dig. Liv. Dis. 35:473-8.

Ying, L, Lin, X, Xie, ZL, Hu, YP, Shi, KQ, 2012: Performance of platelet count/spleen diameter ratio for diagnosis of esophageal varices in cirrhosis: a meta-analysis. Dig Dis Sci. 57, 6:1672-81.

Zaman, A, Decker, T, Lapidus, J, 2001: Risk factors for the presence of varices in cirrhotic patients without a history of variceal hemorrhage. Arch. Intern. Med. 161:2564-70.

Zaman, A, Hapke, R, Flora, K, Rosen, HR, Benner, K, 1999: Factors predicting the presence of esophageal varices or gastric varices in patients with advanced liver disease.

Am. J. Gastroentcrol. 94:3292-6.

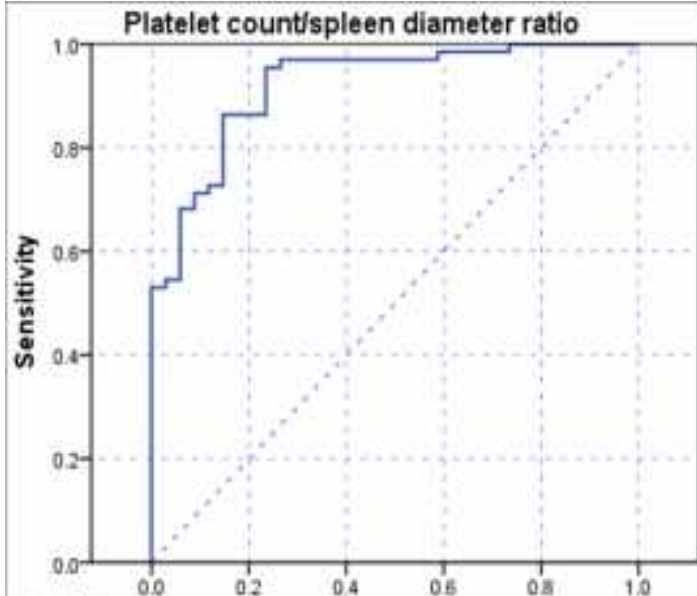

\section{F. 1a}

Fig. 1a: ROC curve of $\mathrm{P} / \mathrm{D}$ ratio to predict $\mathrm{EV}$.

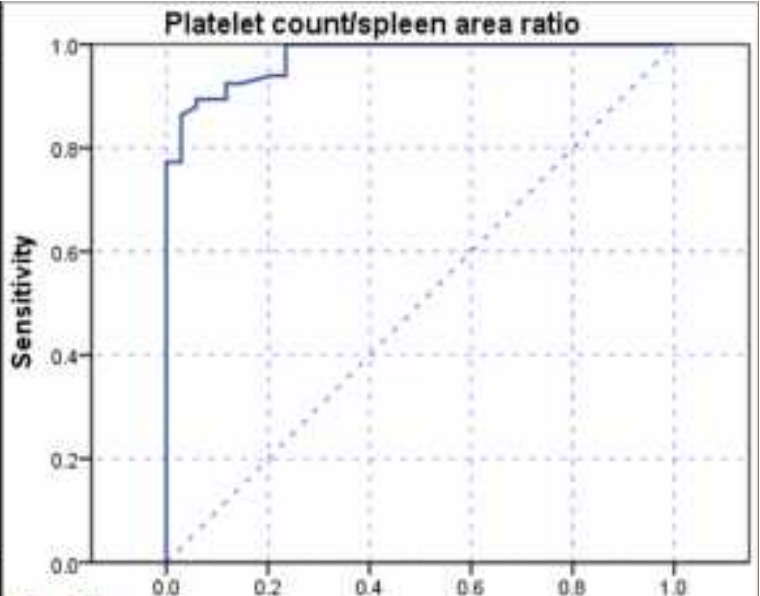

F. 1b

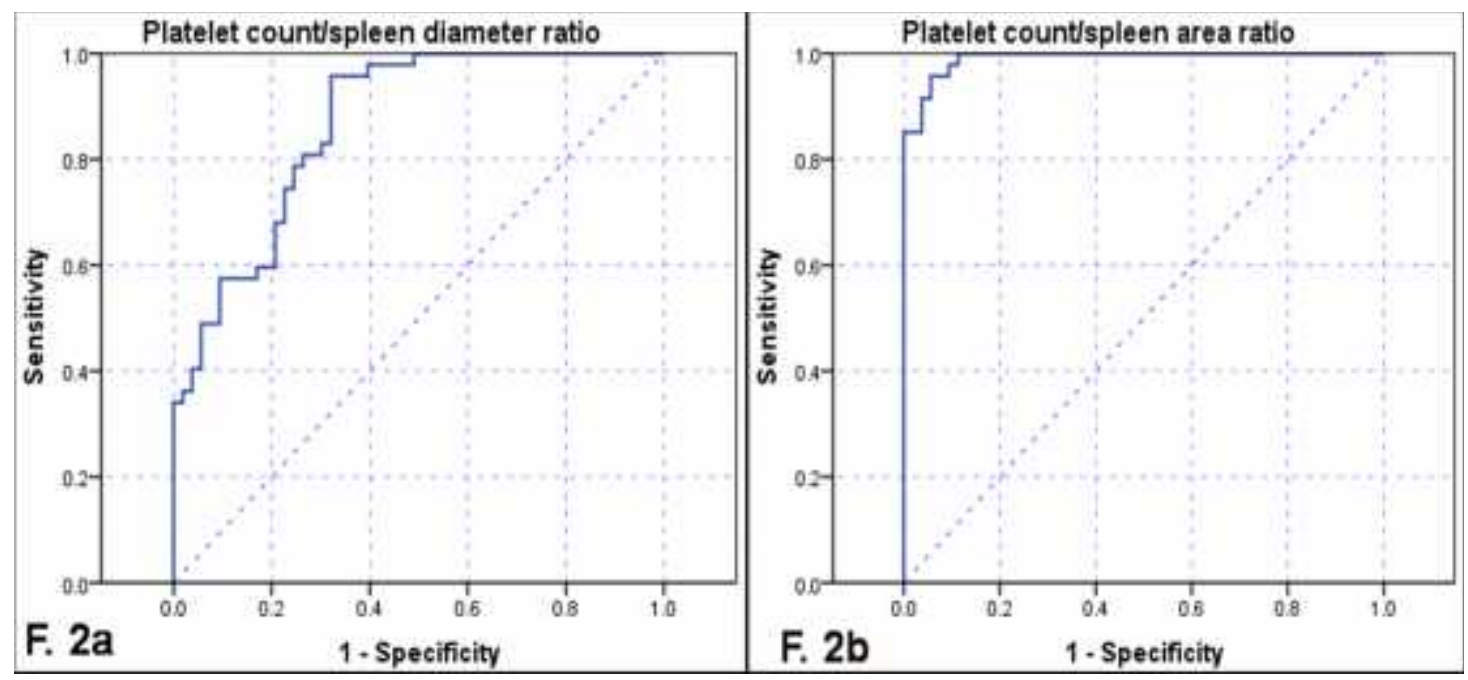

Fig. 2a: ROC curve of $\mathrm{P} / \mathrm{D}$ ratio to predict HREV. Fig. 2b: ROC curve of $\mathrm{P} / \mathrm{A}$ ratio to predict $\mathrm{HREV}$. 